\title{
Corneal transplantation: A new view of life
}

Fardin Amiri ${ }^{1}$, Shahrzad Ghiyasvandian ${ }^{2}$, Elham $\mathrm{Navab}^{3}$, Masoumeh Zakerimoghadam ${ }^{4}$

${ }^{1}$ Ph.D. Candidate of Nursing, Department of Community Health Nursing, School of Nursing and Midwifery, Tehran University of Medical Sciences, Tehran, Iran

${ }^{2}$ Ph.D. of Nursing, Associate Professor, Department of Medical-Surgical Nursing, School of Nursing and Midwifery, Tehran University of Medical Sciences, Tehran, Iran

${ }^{3}$ Ph.D. of Nursing, Assistant Professor, Department of Critical Care and Management Nursing, School of Nursing and Midwifery, Tehran University of Medical Sciences, Tehran, Iran

${ }^{4}$ Ph.D. of Nursing, Assistant Professor, Department of Critical Care Nursing, School of Nursing and Midwifery, Tehran University of Medical Sciences, Tehran, Iran

\section{Type of article: Original}

\begin{abstract}
Background: The consequences of a corneal transplant are evaluated and classified by care providers, but understanding and interpretation of the results varies between patients, and creates different views for them and influences their lives in different ways while these influences are largely unknown.

Aim: This study aimed to explore understanding of new life in patients after corneal transplantation.

Methods: This qualitative study was conducted using a hermeneutic phenomenological approach in Tehran in 2016. Twelve corneal transplant recipients $(7 \mathrm{men}, 5$ women) who were chosen purposefully from penetrating corneal transplant recipients, participated in this study. Semi-structured interviews were used to collect data. The content of the interviews was transcribed and analyzed using Van Manen's methodology.

Results: Data analysis led to the emergence of several main themes, among which "having a new sense" and "fear and hope" were two of the most important themes.

Conclusion: It can be inferred from the overall participants' experiences that corneal transplant has brought about a new look at life for patients. However, transplant-related issues are endless and continuous, and a sense of fear and hope has always surrounded them.
\end{abstract}

Keywords: Corneal transplantation, Patients understanding, Qualitative study

\section{Introduction}

Organ transplantation is considered as one of the most influential innovations of the twentieth century in the field of medical treatments that in recent decades, has improved in parallel with scientific advances in medical technology (1). Corneal transplantation is the most common type of allogeneic transplantation in the world. This surgery has been known as one of the most successful types of tissue graft around the world (2). Advances in microsurgery, immunology, pharmacology, corneal storage technology and equipped eye banks have greatly enhanced the number and success of corneal transplantation $(3,4)$. Currently, 10 Million people worldwide are suffering from diseases which are curable by corneal transplantation (5). Each year about 100,000 cases of corneal transplants are carried out in the world (6), of which about 50,000 cases are in the US (5), 2,500 in the United Kingdom (7) and 3,000 cases are carried out in Iran (8). Success of corneal transplantation in high-risk eyes is far lower than allograft transplantation of organs such as the heart and kidney (4). The success criteria of this transplantation include improved visual acuity, reduced pain and maintaining eye structure (9). People who receive organ transplants always encounter challenges and unexpected events including infection, risk of organ transplant rejection and other

\section{Corresponding author:}

Associate Professor Dr. Shahrzad Ghiyasvandian, Department of Medical-Surgical Nursing, School of Nursing and Midwifery, Tehran University of Medical Sciences, Tehran, Iran.

Tel: +98.2161054325, Fax: +98.2166904252, Email: shghiyas@yahoo.com

Received: November 26, 2016, Accepted: February 03, 2017, Published: April 2017

iThenticate screening: February 02, 2017, English editing: March 28, 2017, Quality control: April 05, 2017

(C) 2017 The Authors. This is an open access article under the terms of the Creative Commons Attribution-NonCommercialNoDerivs License, which permits use and distribution in any medium, provided the original work is properly cited, the use is non-commercial and no modifications or adaptations are made. 
complications (1). For example, depression, anxiety, despair, fear, mood disorders, post-traumatic stress disorder, pain, suicide, feelings of guilt towards the organ donor and high sensitivity to survival have been reported in transplant recipients (10). Transplant rejection and infection are two important post-operative complications of corneal transplant in Iran (11). Because the cornea has no blood vessels, a transplanted cornea does not have a natural strength, and this is a major disadvantage for this transplant as it is possible that even years after the transplantation, the cornea can be detached by mild trauma or physical activity, and can cause serious complications including protrusion of the iris, lens and vitreous, premature or delayed retinal detachment, and can eventually lead to blindness. Patients are aware of this and always suffer and hence, their lives are affected because they should always be under care (12). Furthermore, unlike organs such as kidney and liver, corneal graft is always supplied from a corpse (13). By transplantation, part of another person's body is incorporated into the recipient's body and the fact that they have part of another person's body, does not escape them, leading to complex moral and psychological problems for the patients. The multiplicity of potential factors affecting the individual psyche is that such an experience can be beyond individual tolerance (1). The consequences of corneal transplant is evaluated and classified by care providers, but understanding and interpretation of the results is different for patients, and influences their lives in different ways of which, these effects are largely unknown (14). Several studies have shown that psychological issues are one of the problems that organ recipients encounter before and after transplantation (15). Many transplant recipients, due to mental stress, anxiety and depression have poor quality of life (16). For instance, corneal transplantation affects different aspects of patients' health and its impact based on gender is different. A considerable number of patients are not satisfied with the results of corneal transplantation (14) as it has reduced their social emotions and, as a result, their quality of life (17). In addition, the results have demonstrated that improved vision has a direct association with limitations caused by mood disorders and social performance in patients, so that severe socio-economic restrictions have been shown to increase the risk of corneal transplant rejection (18). Examining and understanding the implications of life with a grafted cornea leads to deep insight in this area that can be added to the body of knowledge of nursing, and help nurses in providing services and optimal care of patients. Nursing interventions should be based on patients' perceptions of their new status which can be attained by nurses through understanding and trying to make clearer the phenomenon of life with a grafted cornea. It has been shown by our research group that so far, no qualitative studies have been performed on the patients' perception of corneal transplant, and only some quantitative studies have pointed out the clinical outcomes of corneal transplant. Hence, the reason that led the researcher to take this issue into consideration was based on the researcher's clinical education experiences as a nurse and instructor, and his interaction with patients who underwent corneal transplantation. During these interactions, each of the patients expressed unique problems and specific requirements that they had. Moreover, the familiarity of the researcher with the qualitative research method (in particular Phenomenology) has urged the researcher to utilize this tool to study the patients' lived experience and to obtain a clear understanding of their experiences. Given the lack of knowledge and research about different aspects of this phenomenon, this study aimed to explore understanding of new life in patients with grafted corneas.

\section{Material and Methods}

\subsection{Research design}

This qualitative study was conducted using hermeneutic phenomenological approach and Van Manen's methodology. Phenomenology as a research method, refers to how subjects in a study experience the intended phenomenon. The intended phenomenon of this study is "Living with a grafted cornea". In order to understand the lived experience of these patients, phenomenology is an appropriate approach to explore their experiences.

\subsection{Van Manen's methodology}

In Van Manen's methodology, six dynamic activities are suggested for conducting phenomenological hermeneutics research which were used in this study as follows (19):

2.2.1. The first step is returning to the nature of the lived experience. When the researcher was working as a nurse on the ward and in the eye surgery operating room, he became interested in explaining life experiences of patients with grafted corneas.

2.2.2. The second step is investigating the lived experience. Researchers in this step searched for people who have had the experience of living with grafted corneas. In this study, participants who had real life experience with the intended phenomenon were selected. Participants in this study were selected among corneal transplant recipients referred to ophthalmology clinics of teaching hospitals affiliated with Universities of Medical Sciences in Tehran. Participants of this study were seven males and five females. The inclusion criteria were being at least eighteen years of age, at least 6 months lived experience with grafted cornea and willingness to participate in this research and share their experiences. Patients who had mental problems were excluded. Semi-structured in-depth interviews 
were used in order to obtain research data. Individual interviews were conducted face-to-face using the Persian language. A total of twelve interviews were conducted with twelve participants. The duration of the interview was between $45-75$ minutes. The location of the interview was chosen by the participants. For this purpose, interviews were conducted either in rooms at the eye clinics of hospitals or in the living places of the participants. At the beginning of the interview, participants were informed of their rights to refuse or leave the study at any time. The oral and written informed consents were obtained from them. With the agreement of the participants, interviews were recorded using a digital voice recorder and after each session, was transcribed verbatim. . Sampling continued until no new themes were extracted from data analysis. Questions were in line with participants' experiences of living with a cornea transplant. For example, questions such as "Please define your life story since your cornea transplant" "Explain to me one day of your life." "What living with a grafted cornea means to you?" In addition, follow-up questions like "please explain more", "Please give an example" were used to further refine data. In addition, the literature review was done at this step.

2.2.3. The third step was reflecting on the essential themes that characterize the phenomenon. Researchers in this phase, using thematic analysis, explained main themes of life phenomenon with a grafted cornea. Van Manen's thematic analysis has suggested three approaches including (a) holistic, (b) selective and (c) a line-by-line approach (19). Holistic and selective approaches were used by researchers in this study. In the holistic approach, researchers were trying to obtain an overview of participants' experiences in such a way that an interview after conversion to a text was considered as a whole, and after reading it several times, overall understanding of the text was written in a few paragraphs. Then, based on the selective approach, the same text was written multiple times. Sentences or phrases that seemed to describe the phenomenon of life with a grafted cornea were selected. Then the selected phrase transformed to become meaningful units. Meaningful units extracted from each interview were written in a column, and according to semantic and conceptual similarity, were placed in a separate category in order to extract more general and more abstract phrases from them.

2.2.4. The fourth step is to describe the phenomenon by using the art of writing and rewriting (Writing activity). In order to attain a powerful explanation about the intended phenomenon, the text of the interviews and extracted themes were revised several times by researchers to achieve a rich phenomenology text.

2.2.5. The fifth step is maintaining a strong and focused relationship to the phenomenon. By considering the main question of the study, researchers were trying to maintain a strong and directional relationship with phenomenon and to avoid superficiality.

2.2.6. The sixth step is balancing the research context by considering the parts and the whole. In this phase, researchers using a holistic and selective approach and by focusing on the central question of the research and continuously moving back and forth between the whole and part, maintained the relationship between parts and the whole.

\subsection{Credibility, transferability, dependability, and confirmability}

In order to meet the criteria of a rigorous study, the researchers performed all research activities based on initial research design. According to Lincoln and Guba (1985), scientific rigor in a qualitative research can be ensured through four criteria of credibility, transferability, dependability, and confirmability (20). In this study, credibility was facilitated by long-term engagement with participants, and findings, integration in data collection, field notes, manuscripts and recordings and observer overview were used. Furthermore, the participants of the study evaluated the theme descriptions for a member check. With credibility being assured, dependability was in turn guaranteed. In order for the transferability of the findings to be judged, we described the findings to a group audience. Finally, Confirmability of the results was performed by providing the participants and four faculty members of nursing with reports, manuscripts and notes. In this study, an audit trail served as a document to assure confirmability.

\subsection{Ethics}

This study was performed based on the principles of the confidentiality of information and obtaining the informed consent for conducting and recording the interviews. Having the right to withdraw from the study at any time was observed as an ethical consideration. The study was approved by the Ethics Committee of Tehran University of Medical Sciences.

\section{Results}

The findings of this study were lived experiences of twelve participants ( 7 men and 5 women) aged between 19-53 years $(34.5 \pm 9.81)$ and with a history of corneal transplants between 1-25 years (9.58 \pm 9.42$)$. Results were analyzed using steps 3 to 6 of Van Manen's method (19). The results of data analysis led to the identification of two themes: the first theme of "having a new sense" had four sub-themes including sense of well-being, improved eyesight, 
satisfaction with the graft, and the feeling of new life. The second theme of "fear and hope" had four sub-themes including hope in God, hope for the future, fear of the future and the fear of blindness (Table 1).

Table 1. The extracted themes and sub-themes

\begin{tabular}{|l|l|}
\hline Themes & Sub-Themes \\
\hline Having a new sense & Sense of well-being \\
\cline { 2 - 2 } & Improved eyesight \\
\cline { 2 - 2 } & Satisfaction with the graft \\
\cline { 2 - 2 } & Sense of new life \\
\hline Fear and Hope & Fear of blindness \\
\cline { 2 - 2 } & Fear of the future \\
\cline { 2 - 2 } & Hope in God \\
\hline & Hope for the future \\
\hline
\end{tabular}

\subsection{Having a new sense}

The study participants had better vision following corneal transplantation and due to the better vision, they developed greater independence, confidence and further progress in their lives. This resulted in a feeling of wellbeing, improved eyesight, satisfaction with the graft, and feeling of a new life in participants that these changes were expressed by several statements.

\subsubsection{Feeling of well being}

Participants in this study did not have good vision before corneal transplant and hence they did not have a normal life. They were reliant on others; they were not able to do their work well and had lots of problems. But corneal transplant has aided their vision and this has allowed them to largely overcome their previous problems and have a sense of well-being. A 26-year-old male participant who had a corneal transplant four years ago stated: "My problem has largely resolved after transplantation. I have normal vision and a normal life; I drive, I can go out with my wife without any problems. My wife says I wish you had had this transplant earlier. The corneal transplant has made me feel a sense of well-being in life, tangibly". A 45-year-old male participant who corneal transplanted 24 years ago said: "I state about corneal transplant again that if someone reaches a point that needs to undergo a corneal transplant, he should do it because it will have good results, especially now that the surgery has advanced and results are better, and anyone who undergoes transplantation will have a better feeling"

\subsubsection{Improving Eyesight}

Most participants expressed that their vision improved after corneal transplantation and this made them do their work easier and more accurately and experience more progress and success in their life. A young man who was student, and the bulk of his duties was to study said: "I do not have much problem now. I always have to study, and previously, I had problems with my eyes, but I am comfortable now. I had to hold a book $10 \mathrm{~cm}$ (max) away from my eyes, but now I am comfortable. Before, I had to read a line 10 times to make sure I wasn't wrong, but I can read easily now". A 28-year-old male participant who corneal transplanted 8 years ago, stated: "My eyesight is great. I have 7/10 vision. Currently I do not wear glasses, but I am supposed to get a pair for study. I go to the store every morning, but previously I couldn't read the prices of goods, but now I can easily see from a distance. Because I could not see well before, I used to miscalculate the prices, but now I'm fine, I calculate easier. I couldn't go out alone before, but now I just go out and do my work by myself. Before, I was not comfortable working with a computer as it was hard for me, but now I can work with a computer easily"

3.1.3. A sense of new life

The participants in this study stated that they had a lot of problems before the transplantation, and because of those problems they had limited communication with others and mostly preferred to be alone. But transplantation has caused their problems to be largely resolved, to live easier and experience rebirth and a new life. A 25 -year-old male participant who had a transplant 1.5 years ago said: "I started a new life after transplantation. Before, I was really disappointed due to my problem as it was very hard for me, especially at night I used to stay in a dark room because I could not tolerate the light. I was really disappointed but I was told that if you receive a graft you will get better. I doubted it and I was afraid of the surgery. My family forced me to transplant and now I'm thankful, I'm much better than before. It seems a new life has begun for me" A 28-year-old male participant who transplanted 8 years ago mentioned: "After transplantation a new life begins for a person, as if the person evolves and is reborn again. One's life changes significantly. Life gets better". 


\subsubsection{Satisfaction with the graft}

Most study participants were satisfied with the transplanted cornea. They said before transplantation, they did not have good eyesight and could only do so many things. They had a difficult life and were not satisfied with their lives. But their vision improved after transplantation, and now they can do their work better and do other things (like driving) that they were not previously able to do. A 25 -year-old male participant who transplanted 1.5 years ago said: "I am satisfied with the graft. If I was told now that it is better for me to do the transplantation again, I would be ready to do that". A 31-year-old female participant who transplanted 4.5 years ago, said: "Before my transplant I could not go out, but now I am very comfortable, and I can go out whenever I want. I used not to go out at night because the light bothered both my eyes and I had to close them. Now, the light doesn't bother my eyes even in the sunshine, but it was difficult before, as I could not see at all. With minor vision, I would see a hundred people instead of one, but thank God, now I can see people individually"

\subsection{Fear and Hope}

Participants in the study developed more hope toward vision improvement and refinements of life after corneal transplant. They were also aware of the possible complications of the transplant restoration process, and had several concerns and fears that led to feelings of fear for the future, fear of blindness, faith in God and hope for the future.

\subsubsection{Fear of the future}

Most participants expressed that they saw an ambiguous future ahead, and that they were afraid of the unknown future. They were deeply concerned about what might happen in the future as well as what impact their eye problems will have on them and their families. A 25 -year-old male participant who transplanted 5 years ago said: "Even healthy eyes are affected by aging, so what about our grafted eyes with poor vision! It is unclear what will happen to us. I am very scared". A 26-year-old male participant who grafted four years ago stated: "As I am becoming a father soon, I'm a little bit worried about whether corneal disorder is hereditary or not? I mean is it possible the problem will be transferred to my child? The ultrasound and test results show that there is no problem yet. I hope there will be no problem in the future"

\subsubsection{Fear of blindness}

Most participants had a great fear of complications of corneal transplantation and blindness. They expressed this fear through various statements. This fear had greatly impacted their lives and subsequently, motivated them to better take care of their eyes in order to maintain the graft. A 33-year-old female participant who had corneal transplant two years ago said: "There is always a fear in my heart that my eye might not see anymore, even after the transplantation when the doctor opened my eyes for examination for the first time, I fainted out of fear that I might not see again. I have the same feeling now and when I wake up in the morning I first close my healthy eye to make sure if I can see with my grafted eye. It is not too bad! My husband says that there is a layer around your eyes; maybe the cornea is protruding. This fear is always in my heart". A 29 -year-old female participant who had corneal transplant 6 years ago said: "Sometimes I think what if I lose my eyesight? I am very afraid of this issue, my nerves are shattered. I cry at night, I am scared of losing my eyes. To put it bluntly, I am very afraid"

\subsubsection{Hope to God}

Participants in the study had great concern about graft rejection and blindness. As they had experienced low vision and its subsequent problems, they noted that they were hoping to have good vision. Depending on their belief in God and His will, they had placed their hopes on the mercy of God for maintaining the transplant and improving their vision. A 31-year-old female participant who had a corneal transplant a year ago said: "When my corneal reconstructive surgery failed I became depressed and full of despair. Thank God, people helped me and gave me morale. Thank God medical science has made such a tremendous progress that every problem can be overcome. Those around should offer their morale and help. I used to cry during the first 2 months; I would say maybe my eyesight will not return and I may lose my vision. But thank God, my transplant was successful and I gained better vision. What I did not expect, happened to me. I had to encourage myself as I was disappointed. One must have the morale and hope to God, and then others will help too". A 25 -year-old male participant transplanted 1.5 years ago stated: "It took some time for my graft to be repaired. I very much hope that my vision becomes better. To quote my doctor, "it takes 2 years until stitches can be removed". So, I have to wait to see what God wants. God willing, I hope to get good vision"

\subsubsection{Hope for the future}

Participants expressed that corneal transplant brought about better vision. Considering the understanding they obtained about the transplantation, and based on their doctor's opinion and the experiences of people who had already gone through the procedure, they were hoping their vision was going to be further improved and the problems would be reduced in the future". A 25 -year-old male participant who transplanted 1.5 years ago said: "I hope the problems that have been created due to corneal transplantation in my everyday life will be resolved; I hope 
my vision will get better to be able to wear glasses". A 33-year-old female participant who had transplanted two years ago stated: "I try to take good care of my eye, and try not to think about people saying that I will be coming to the clinic for the rest of my life, and instead, think about the ones saying that I will be fine within next 5 years. I try to take care of my eye properly then it will become better in 5 years and then I won't need to commute (refer) to here"

\section{Discussion}

The results of this study showed that the patients' understanding of new life after the corneal transplant included two themes of 1) having a new sense (with four sub-themes including sense of well-being, improved eyesight, satisfaction with the graft, and a sense of new life), and 2) fear and hope (with four sub-themes including fear of the future, fear of blindness, hope in God and hope to the future). Participants pointed out the good feelings they had as a result of improved vision after corneal transplant. Due to poor vision before transplantation, the participants used to encounter several restrictions in their personal lives, families and their careers. These restrictions had reduced their social relationships with others and caused them to feel depressed and incapable of doing their work properly. But after transplant, these limitations and problems, due to better vision, greatly reduced and they were able to live and communicate with others more easily, which led to their satisfaction. The results of a study by Musch et al. showed that patients had better visual function after corneal transplantation and as a result, they were able to do everyday tasks better and this created a sense of well-being in them (21). Bandela et al. also indicated that corneal transplantation improved vision in patients and as they could perform vision-related tasks better, this caused more satisfaction in patients (22). In addition, Fasolo et al. reported that patients who had undergone cornea transplantation were satisfied with the outcome (14). Tomlie et al., in a study which was carried out on patients who had undergone coronary artery bypass graft $(\mathrm{CABG})$, showed that most of the patients declared that their physical and psychological problems after CABG were dropped and they had a sense of well-being (23). Mahdavi and Naghib also showed that kidney transplantation improved physical and mental growth and extended the life of children, and they had a sense of well-being after transplantation (24). But the results of a study by Yildiz et al., indicated that in patients who had undergone corneal transplant surgery due to keratoconus, despite better vision, problems still remained in association with vision-related quality of life (25). Participants stated that after corneal transplant their daily activities and social interactions had improved as a result of better eyesight. These factors made them feel they were entering into a new world and felt a new life that was very pleasant and satisfactory for them. Heart patients who had undergone CABG had expressed a feeling of rebirth after CABG (26). Ghadami et al. examined life experience of kidney transplant patients and reported the content of "rebirth and feeling free from constraints" in these patients (27). In the present study, the concept of "having a new feeling" which resulted from deep understanding of patients, is in line with outcomes of some previous studies. Additionally, in this study, the concept of "having a new life" has also been achieved, which is a very important aspect from the patients' perspective. Although this aspect has not been achieved in the previous studies on corneal transplant, but it has been reported by some qualitative studies on other organ transplantation. Awareness of the patients' feelings and subsequent changes in their lives further indicates the importance of a corneal transplant and taking care of it. This helps nursing staff to improve the quality of care and to provide appropriate care according to the circumstances and patients' understanding. Participants of this study expressed mixed feelings of hope and fear following corneal transplantation. They had gained awareness about corneal transplants, maintaining the transplant and its complications. They were aware that one of the serious and permanent complications of corneal transplant is the chance of transplant rejection. This caused a great fear of the future and blindness in patients. The fear of blindness resulted from their previous experiences of low vision and its subsequent problems. The patients knew that, due to blindness, their connections with the outside world would largely be disrupted, their independence would reduce and they could no longer follow a natural and comfortable life. Shortt et al. reported that the fear of blindness is a major fear worldwide. Fear of blindness among 50-64-year-old Americans is twice as great as the fear of developing heart disease. Participants expressed that blindness would be the worst experience in life, and good eyesight is one of the most important things in life (28). In addition, Seiler et al. reported the fear of transplant rejection as a central theme in patients who had undergone lung transplantation (29). Results of a study by Cohen et al. showed that fear, as a general fact, existed in patients who had undergone bone marrow transplants. Fears of losing control and confidence over the body were mixed together. Fear had changed the patients' view of their lives and made them feel they required assistance (30). The results of this study about fear are consistent with the results of previous studies. Considering that fear of transplant rejection and blindness can profoundly affect patients' quality of life and create need for help in these group, all members of the healthcare team and especially nurses, should take this issue into account and utilize all the measures necessary for eliminating fear and anxiety of these patients. Hence, improving the communication between nurses and patients, providing necessary training, providing high quality care and 
lifetime follow-up can help to achieve this objective. Hope in God and hope for the future are other sub-themes of this study. Despite the fear of the future and blindness, there were narratives of hope in God and hope for the future. Patients' vision had improved, and in light of this improved vision, they were better able to interact and communicate with the environment and others and to do their work easier. They also became aware of satisfying experiences of other transplant patients that all together, created more hope for the future in these patients. Corneal transplant is the only promising way to treat blindness caused by corneal diseases (31). Results of the study by Saleh and Brockopp showed that hope was the main theme in patients with bone marrow transplant, to overcome their disease. In order to increase their hope they used six strategies as follows: relationship with God, relationships with others, positive thinking, life expectancy, living in the present moment, and continuous cultivation of virtue (32). In contrast, Zegarowa et al. reported that patients' hope had not increased after kidney transplant (33). Participants of this study, by the grace of God, had high levels of hope for better vision and maintaining the graft, and they believed that treatment is in the hands of God and to entrust everything to God. Their hope caused them to experience less fear and concern and more calmness about their transplants. They asserted that hope to God had an important role in overcoming the mental condition after transplantation. Raiesdana et al. reported the "trust in God" as a sub-theme in the spiritual experiences of heart transplant recipients (34). According to the fact that the participants of this study lived in a society in which belief in God and His will played an important role in people's lives, it seems internalization of such beliefs is rooted in cultural issues of their community and beyond that rooted in human nature. This causes the patients' attitude to change in a positive direction; hence, this must be the priority of the care team, especially nurses, in order to provide care based on a holistic approach and different aspects of human nature.

\section{Limitations}

This study was performed on a limited number of clients with corneal transplantation. The small sample size and the nature of the study limited the ability to generalize the results. However, as with all qualitative studies, the results were not intended to be generalized.

\section{Conclusions}

It can be inferred from the overall opinions of participants that corneal transplantation creates a new feeling and a new life for them. However, transplantation and its relevant issues, is an endless, continuous and sensitive subject which always encompasses a sense of fear and hope. The patients need constant assistance and awareness in order to encounter this issue, which can be accomplished by nurses as the professional care givers so that they can easily offer their help to patients in maintaining graft and eyesight improvement.

\section{Acknowledgments:}

This article is part of the doctoral dissertation in nursing conducted at Tehran University of Medical Sciences. Hereby, the author would like to thank all the relevant authorities and also thank all participants for their meaningful collaboration in this study.

\section{Conflict of Interest:}

There is no conflict of interest to be declared.

Authors' contributions:

All authors contributed to this project and article equally. All authors read and approved the final manuscript.

\section{References:}

1) Gaum L, Reynolds I, Jones M, Clarkson A, Gillan H, Kaye S. Tissue and corneal donation and transplantation in the UK. Br J Anaesth. 2012; 108: 43-7. doi: 10.1093/bja/aer398. PMID: 22194430.

2) Duman F, Kosker M, Suri K, Reddy JC, Ma JF, Hammersmith KM, et al. Indications and outcomes of corneal transplantation in geriatric patients. Am J Ophthalmol. 2013; 156(3): 600-7. doi: 10.1016/j.ajo.2013.04.034. PMID: 23769195.

3) Gordon MO, Steger-May K, Szczotka-Flynn L, Riley C, Joslin CE, Weissman BA, et al. Baseline factors predictive of incident penetrating keratoplasty in Keratoconus. Am J Ophthalmol. 2006; 142(6): 923-31. doi: 10.1016/j.ajo.2006.07.026. PMID: 17157577.

4) Brown MM, Brown GC. Outcome of corneal transplantation. British journal of ophthalmology. 2002; 86(1): 2-3. doi: 10.1136/bjo.86.1.2.

5) Eye bank association of America. Penetrating keratoplasy. Available from: https://www.restoresight.org. 2015. 
6) Gupta N, Vashist P, Tandon R, Gupta SK, Dwivedi S, Mani K. Prevalence of corneal diseases in the rural Indian population: the Corneal Opacity Rural Epidemiological (CORE) study. Br J Ophthalmol. 2015; 99(2): 147-52. doi: 10.1136/bjophthalmol-2014-305945. PMID: 25395684.

7) Jones MN, Armitage WJ, Ayliffe W, Larkin DF, Kaye SB. Penetrating and deep anterior lamellar keratoplasty for keratoconus: a comparison of graft outcomes in the United Kingdom. Investigative ophthalmology \& visual science. 2009; 50(12): 5625-9. doi: 10.1167/iovs.09-3994. PMID: 19661238.

8) Eye bank of I.R. Iran. Penetrating keratoplasty. Available from: https://www.iraneyebank.org. 2015.

9) Fasolo A, Capuzzo C, Fornea M, Franch A, Birattari F, Carito G, et al. Risk factors for graft failure after penetrating keratoplasty: 5-year follow-up from the corneal transplant epidemiological study. Cornea. 2011; 30(12): 1328-35. doi: 10.097/ICO.0b013e318206895a. PMID: 21926910.

10) Tong A, Morton R, Howard K, Craig JC. Adolescent experiences following organ transplantation: a systematic review of qualitative studies. J Pediatr. 2009; 155(4): 542-9. doi: 10.1016/j.jpeds.2009.04.009. PMID: 19555971.

11) Zare M, Javadi MA, Einollahi B, Karimian F, Rafie AR, Feizi S, et al. Changing indications and surgical techniques for corneal transplantation between 2004 and 2009 at a tertiary referral center. Middle East Afr J Ophthalmol. 2012; 19(3): 323. doi: 10.4103/0974-9233.97941. PMID: 22837628, PMCID: PMC3401804.

12) Jafarinasab MR. Hasani HR, Esfandiari H, Kheiri B, Feizi M. Traumatic Wound Dehiscence Following Corneal Transplantation. Bina. 2013; 18(3): 315-20.

13) Soleymani MR, Javadi MA, Zare M, Sharifi A. Indications for Corneal Transplantation in Labbafinejad Medical Center, Tehran, Iran. Bina. 2005; 10(5): 597-603.

14) Fasolo A, Capuzzo C, Fornea M, Frigo AC, Monterosso C, Zampini A, et al. Health status and patient satisfaction after corneal graft: Results from the corneal transplant epidemiological study. J Ophthalmol. 2012; 2012: 230641. doi: 10.1155/2012/230641. PMID: 22619701, PMCID: PMC3348637.

15) Gross CR, Kreitzer MJ, Thomas W, Reilly-Spong M, Cramer-Bornemann M, Nyman JA, et al. Mindfulness-based stress reduction for solid organ transplant recipients: a randomized controlled trial. Altern Ther Health Med. 2010; 16(5): 30-8. PMID: 20882729 , PMCID: PMC3076132.

16) Corruble E, Durrbach A, Charpentier B, Lang P, Amidi S, Dezamis A, et al. Progressive increase of anxiety and depression in patients waiting for a kidney transplantation. Behav Med. 2010; 36(1): 32-6. doi: 10.1080/08964280903521339. PMID: 20185399.

17) Mak S, Wong AC. Vision-related quality of life in corneal graft recipients. Eye (Lond). 2012; 26(9): 124955. doi: 10.1038/eye.2012.130. PMID: 22744389, PMCID: PMC3443836.

18) Chua PY, Azuara-Blanco A, Hulme W, Jones MN, Mustafa MS, Kaye SB, et al. The effect of socioeconomic deprivation on corneal graft survival in the United Kingdom. Ophthalmology. 2013; 120(12): 2436-41. doi: 10.1016/j.ophtha.2013.07.050. PMID: 24139153.

19) Van Manen M. Writing in the dark: Phenomenological studies in interpretive inquiry. London, Ont: Althouse Press; 2001.

20) Lincoln Y, Guba E. Naturalistic Inquiry. London: Sage Publications Inc; 1985.

21) Musch DC, Farjo AA, Meyer RF, Waldo MN, Janz NK. Assessment of health-related quality of life after corneal transplantation. Am j Ophthalmol. 1997; 124(1): 1-8. doi: 10.1016/S0002-9394(14)71636-8. PMID: 9222225.

22) Bandela PK, Satgunam P, Garg P, Bharadwaj SR. Corneal Transplantation in Disease Affecting Only One Eye: Does It Make a Difference to Habitual Binocular Viewing? PloS One. 2016; 11(3): e0150118. doi: 10.1371/journal.pone.0150118. PMID: 26938450, PMCID: PMC4777496.

23) Tolmie EP, Lindsay GM, Belcher PR. Coronary artery bypass graft operation: Patients' experience of health and well-being over time. Eur J Cardiovasc Nurs. 2006; 5(3): 228-36. doi: 10.1016/j.ejcnurse.2006.01.007. PMID: 16627003 .

24) Mahdavi R, Naghib M. Kidney transplantation in children: results of ten years experience in Imam Reza hospital. Medical Journal of the Islamic Republic of Iran (MJIRI). 2002; 16(3): 145-9.

25) Yildiz EH, Cohen EJ, Virdi AS, Hammersmith KM, Laibson PR, Rapuano CJ. Quality of life in keratoconus patients after penetrating keratoplasty. Am j Ophthalmol. 2010; 149(3): 416-22. doi: 10.1016/j.ajo.2009.10.005. PMID: 20172068.

26) Abbasi M, Mohammadi N, Nikbakht Nasrabadi A, Sadegi T. Experiences of Living with Coronary Artery Bypass Graft: a Qualitative Study. Hayat. 2014; 19(4): 38-47.

27) Ghadami A, Memarian R, Mohammadi E. A qualitative study of hemodialysis as a grueling experience versus kidney transplantation as a rebirth. Arak Medical University Journal. 2012; 15(4): 47-62. 
28) Shortt AJ, Tuft SJ, Daniels JT. Corneal stem cells in the eye clinic. Br med bull. 2011; 100(1): 209-25. doi: 10.1093/bmb/ldr041. PMID: 21926089.

29) Seiler A, Klaghofer R, Drabe N, Martin-Soelch C, Hinderling-Baertschi V, Goetzmann L, et al. Patients' Early Post-Operative Experiences with Lung Transplantation: A Longitudinal Qualitative Study. Patient. 2016: 9(6): 547-57. doi: 10.1007/s40271-016-0174-z. PMID: 27139224.

30) Cohen MZ, Ley CD, editors. Bone marrow transplantation: the battle for hope in the face of fear. Oncology Nursing Forum; 2000.

31) Tigga MJ, Agarwal PC, Gupta S, Singh H, Khan N, Laad S. Level of awareness and attitude regarding eye donation among nursing and paramedical staff working in tertiary care center. J Evid Based Med Health. 2016; 3(44): 2189-93. doi: 10.18410/jebmh/2016/486.

32) Saleh US, Brockopp DY. Hope among patients with cancer hospitalized for bone marrow transplantation: a phenomenologic study. Cancer Nurs. 2001; 24(4): 308-14. doi: 10.1097/00002820-200108000-00012. PMID: 11502040.

33) Zegarow P, Jankowska M, Sańko-Resmer J, Durlik M, Grzeszczyk M, Pączek L, editors. Kidney transplantation does not increase the level of basic hope or life satisfaction compared with hemodialysis in patients with chronic kidney disease. Transplantation proceedings. Elsevier. 2014.

34) Raiesdana N, Peyrovi H, Mehrdad N. Spiritual experience in heart transplant recipients in Iran. Iranian Journal of Cardiovascular Nursing. 2013; 2(3): 44-53. 